\section{Response to González-Henríquez and Saavedra-Santana}

We are very pleased to have the opportunity to review the interesting development reported by Gonzalez-Henriquez and Saavedra-Santana in their paper that was influenced by our earlier paper. ${ }^{1}$

It might be of interest to Gonzalez-Henriquez and Saavedra-Santana to review some of our subsequent work that had as its foundation our 1992 paper and that has recently appeared. ${ }^{2,3}$

University of Toronto, Canada

AKS Jardine

\section{References}

1 Makis V and Jardine AKS (1992). Optimal replacement policy for a general model with imperfect repair. J Opl Res Soc 43: 111120.

2 Makis V, Jiang X and Cheng K (2000). Optimal preventative replacement under minimal repair and random repair cost. Math Opns Res 25: 141-156.

3 Makis V, Jiang X, Jardine AKS and Cheng K (2000). A general framework for analyzing maintenance policies. In: Ben-Daya M, Dufua SO and Raouf A (eds). Maintenance Modelling and Optimization. Kluwer: Boston, pp 185-199. 